\title{
Abono Permanência em uma instituição federal de ensino superior: aplicação e desdobramentos
}

Roberta Martins Xavier e Magnus Luiz Emmendoerfer

\section{Introdução}

No Brasil, embora pouco conhecido e aparentemente recente, o Abono Permanência já existe há algum tempo. Historicamente, o Abono surgiu por decreto do príncipe regente Dom Pedro de Alcântara, baixado em 1ํㅡㄹ de outubro de 1821, no qual se previu que aqueles, que tendo completado o tempo e não quisessem se aposentar, permaneceriam em atividade e teriam abono adicional de um quarto do salário. Tal benefício, pago até 1991, já na previdência moderna, é conhecido como Abono Permanência em Serviço (Martins, 2004).

Após esse período, o Abono Permanência voltou ao cenário público em 2003, na Reforma da Previdência no Serviço Público, quando foi instituído pela Emenda Constitucional no ${ }^{\circ}$ 41/03.

Como o próprio nome diz, o Abono é um bônus, um "plus" (SERTÃo, 2005). Significa algo que se acrescenta, daí ser o Abono de Permanência uma gratificação concedida ao servidor que, tendo alcançado todos os requisitos para se aposentar, opte por permanecer em atividade (MARTINs, 2004). 
Alguns autores e instituições explicam melhor o que vem a ser esse benefício. A Secretaria Geral de Recursos Humanos da Universidade Federal de São Carlos descreve os principais pontos da Reforma Previdenciária aprovada pela Emenda Constitucional no 41 de 31/12/2003. Entre os pontos, está o Abono Permanência: "equivalente a contribuição previdenciária para os servidores que tenham completado as exigências para aposentadoria voluntária e que optem por permanecer em atividade até completar as exigências para aposentadoria compulsória: 70 anos de idade" (UfSCAR, 2004).

Sertão (2005) aponta o duplo objetivo do Abono: a) incentivar o servidor que implementou os requisitos para aposentarse a permanecer na ativa, pelo menos até completar as exigências para aposentadoria compulsória; e b) promover maior economia ao Estado que, com a permanência do servidor na ativa, consegue postergar a dupla despesa de pagar proventos a esse e remuneração ao que o substituirá.

Em outro ponto de vista, Martins (2004) afirma que as duas finalidades específicas do abono seriam as seguintes: 1) substituir a isenção da contribuição previdenciária, antes concedida a servidores que alcançassem os requisitos para se aposentar e optassem por permanecer em atividade; e 2) manter a arrecadação dos fundos de previdência, sendo que o servidor continuará a pagar mensalmente os valores atinentes à contribuição previdenciária, sendo-lhe o abono pago pelos cofres do Estado, ou seja, a arrecadação da previdência é mantida.

A primeira justificativa acima, a de substituir a isenção da contribuição previdenciária, pode ser explicada pelo fato de que, antes da Emenda Constitucional que criou o Abono Permanência, existia a "isenção de contribuição previdenciária", ou seja, os servidores que completassem as condições para aposentadoria e continuassem trabalhando seriam isentos de tal contribuição. Já a segunda justificativa, manter a arrecadação dos fundos de previdência em que "o imposto de renda será calculado sobre o salário mais o abono", faz com que o contribuinte pague mais imposto (MArTins, 2004).

Com isso, dado o objetivo do Abono Permanência, este artigo tem como problema de pesquisa a seguinte questão:

Após a Emenda Constitucional no 41/2003, de que forma ocorreu a implementação do benefício Abono Permanência em uma instituição federal de ensino superior e que implicações esse benefício acarretou a seus servidores e à própria instituição?

Sendo assim, o objetivo principal deste artigo é descrever a implementação do Abono Permanência e suas consecutivas implicações para tal instituição e para seus servidores. Para o alcance do objetivo geral desta pesquisa, faz-se necessário: a) identificar como e quando o Abono Permanência foi implementado; b) identificar de que maneira os servidores dessa instituição tomaram conhecimento do benefício; c) levantar e caracterizar os servidores que recebem o benefício; d) identificar as contribuições e possíveis limitações da implementação do Abono na instituição.

Embora seja um assunto pouco tratado, espera-se que este artigo contribua de forma significativa para a compreensão do Abono como um benefício e de sua operacionalização na administração pública. Espera-se também que contribua para discussões e melhor entendimento dos benefícios sociais na gestão de pessoas, suas contribuições, vantagens, desvantagens 
e possíveis limitações para funcionários e organizações. Tudo isso tendo em vista a importância desse tipo de recompensa em uma organização e suas implicações no dia a dia dos profissionais.

\section{A Gestão de Pessoas e os benefícios sociais}

O crescimento da oferta dos benefícios sociais tem presença recente nas organizações. A própria história das organizações demonstra que não foi sempre assim. "Apenas na década de 60 e, mais fortemente, na de 70 , os sindicatos começaram a pressionar no sentido de assegurar maiores benefícios às pessoas, exigindo segurança e condições de trabalho especiais" (ARAÚjo, 2006, p. 168).

Mas afinal, o que são esses benefícios e qual sua importância nas organizações? A literatura sobre gestão de pessoas menciona que benefícios são certas regalias e vantagens concedidas pelas organizações, por questões legais e/ou deliberadas, a título de recompensa de adicional dos salários à totalidade ou à parte de seus funcionários. De acordo com Bratton e Gold (1999, p. 241), os benefícios são formas de recompensas individuais, que incluem benefícios assistenciais, como pensões, saúde privada e seguro dental, e licenças pagas, como educação de tempo integral e deveres cívicos. Esses incluem uma variedade de facilidades e vantagens oferecidas pela organização, como assistência médico-hospitalar, seguro de vida, alimentação subsidiada, transporte, pagamento de tempo não trabalhado, planos de pensão ou aposentadoria. Segundo Lacombe (2005, p. 147), além disso, existem os benefícios proporcionados pelo status, pelo reconhecimento, pelo conforto nas condições de trabalho e tudo o mais que causa satisfação às pessoas que trabalham em uma empresa.

Hoje, os benefícios fazem parte dos atrativos com que as organizações retêm seus talentos e estão intimamente relacionados a aspectos da responsabilidade social das organizações. "Antes vistos como uma vantagem oferecida pelo empregador, os benefícios atualmente são considerados direitos reivindicados por todos os funcionários, e se tornaram uma das áreas da

"Os beneficios

fazem parte dos

atrativos com que

as organizações retêm

seus talentos e estão

intimamente

relacionados a

aspectos da

responsabilidade

social das

organizações."

legislação trabalhista e de litígio que crescem mais rapidamente" (BOHLANDER, 2005, p. 310). Segundo Bohlander (2005), os principais objetivos da maioria dos programas de benefícios são: aprimorar a satisfação do funcionário no trabalho, atender aos requisitos de saúde e segurança, atrair e motivar os funcionários, reduzir a rotatividade, manter uma posição competitiva favorável. França (2007) diz que os pacotes de 
benefícios foram desenhados para ir ao encontro das necessidades básicas da maioria dos empregados e que foram transformando-se em mecanismo de atração e retenção de pessoas talentosas.

Bohlander (2005, p. 313) apresenta as vantagens e desvantagens dos planos de benefícios. As vantagens são: a) os funcionários selecionam benefícios que atendem às suas necessidades individuais; b) as seleções de benefícios adaptam-se a uma força de trabalho (diversificada) em constante mudança; c) os funcionários ganham mais entendimento dos benefícios oferecidos e dos custos implícitos; d) os empregados maximizam o valor psicológico de seu programa de benefícios, pagando apenas pelos benefícios altamente desejados; e) os empregadores limitam os custos de benefícios, permitindo aos funcionários "comprar" benefícios apenas até uma quantia máxima (definida); f) os empregadores ganham vantagem competitiva no recrutamento e na retenção dos funcionários.

Como desvantagens têm-se: a) a má seleção dos benefícios concedidos aos funcionários resulta em custos financeiros indesejáveis; b) há certos custos adicionais para estabelecer e manter o plano flexível; c) os funcionários podem escolher benefícios de alto uso para eles, que aumentem os custos de prêmio para o empregador.

Muitos funcionários não se dão conta do valor de mercado e do elevado custo de seus benefícios. De acordo com Cooperse Lybrand, consultoria especializada em remuneração, nos Estados Unidos, em 1994, os benefícios representavam, em média, 25\% dos custos totais da folha de pagamento e existe uma dificuldade de reduzir benefícios, uma vez que foram concedidos (FrançA, 2007). Diante disso, faz-se necessário, para o sucesso da aplicação dos benefícios sociais, que os ideais geradores dessa ação sejam verdadeiros, justos e solidários, assim como o comprometimento das pessoas envolvidas na ação.

\section{O que diz a Emenda Constitucional no $41 / 2003$}

O Fundamento Legal apresenta-se da seguinte forma:

- Art. 40, \ 19 da CF, com redação dada pela EC 41/03: O servidor de que trata este artigo, que tenha completado as exigências para aposentadoria voluntária estabelecidas no $\int 1^{\circ}$, III, a (65 anos de idade + 35 anos de contribuição/homem - 60 anos de idade +30 anos de contribuição/ mulher), e que opte por permanecer em atividade fará jus a um abono de permanência equivalente ao valor da sua contribuição previdenciária até completar as exigências para aposentadoria compulsória contidas no $\int 1^{\circ}$, II.

- Art. 2, 5 5o da EC 41/03: O servidor de que trata este artigo, que tenha completado as exigências para aposentadoria voluntária estabelecidas no caput, e que opte por permanecer em atividade, fará jus a um abono de permanência equivalente ao valor da sua contribuição previdenciária até completar as exigências para aposentadoria compulsória contidas no art. 40, \ $1^{\circ}$, II, da Constituição Federal.

- Art. 3, ऽ 10 da EC 41/03: O servidor de que trata este artigo que opte por permanecer em atividade, tendo completado as exigências para aposentadoria voluntária e que conte com, no mínimo, 25 anos de contribuição, se mulher, ou 30 anos de contribuição, se homem, fará jus a um abono de permanência equivalente ao valor da sua contribuição previdenciária, até completar as exigências para aposentadoria compulsória con-

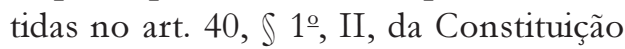
Federal. 
Simplificando os artigos da Emenda Constitucional, o Abono Permanência é concedido ao servidor que completou as exigências para se aposentar ou que preenche determinados requisitos - que são quase todos os requisitos para se aposentar, seja aposentadoria integral ou proporcional.

Esse abono é equivalente ao valor da sua contribuição previdenciária e é assegurado até, no máximo, a idade para aposentadoria compulsória: 70 anos.

\section{O Abono Permanência como benefício social}

Para Araújo (2006, p. 169), “os benefícios sociais correspondem às condições de trabalho que as organizações oferecem para manter as pessoas". Esses benefícios funcionam como verdadeiros atrativos; além de manter as pessoas na organização, garantir necessidades e urgências pessoais e profissionais, geram melhor produtividade e maior comprometimento com a empresa (ARAújo, 2006).

Em suas palavras, Araújo (2006) revela as motivações pelas quais os benefícios são oferecidos. "Os benefícios sociais são oferecidos por motivações diferentes e de acordo com os objetivos de cada organização" (ARAÚJo, 2006, p. 169). Segundo ele, as organizações podem de várias formas desenvolver essa prática, e esse processo tem demonstrado crescimento positivo ao longo dos anos.

Bohlander (2005, p. 323) diz que, "originalmente, os planos de aposentadoria baseavam-se em uma filosofia de recompensa, e eram considerados sobretudo como um meio de manter os funcionários, recompensando-os por ficarem na empresa até se aposentar". "Entretanto, em virtude dos direitos exigidos, negociados na maioria dos contratos sindicais e, mais recentemente, garantidos por lei, as aposentadorias agora se baseiam em filosofia de ganhos" (BOHLANDER, 2005, p. 323).

No caso do Abono Permanência, o benefício é requerido por vontade própria do servidor público que, ao completar as exigências para aposentadoria voluntária, opte por permanecer em atividade. Esse é oferecido pelas instituições públicas e serve de incentivo para que o servidor permaneça em atividade e prorrogue sua aposentadoria (SERTÃO, 2005).

Importante salientar que "a percepção de cada organização funciona de forma diferente, cada uma com seu perfil, com seus profissionais, práticas e objetivos" (ARAÚjo, 2006, p. 183).

Logo, a pretensão aqui não é a de comparar tal benefício implementado com outras instituições e organizações, e sim compreender o seu funcionamento, perfil, funcionários (servidores) e objetivos alcançados, ou ainda, suas implicações tanto para quem requer o benefício quanto para a instituição em questão.

\section{A natureza jurídica do benefício}

Martins (2004) aponta que a Emenda Constitucional no 41 não deixou bem clara a natureza jurídica do AbonoPermanência, ou seja, não definiu se trata-se de uma verba de caráter indenizatório ou de caráter remuneratório.

Verbas de caráter indenizatório são aquelas previstas em lei e que se destinam a indenizar o servidor por gastos em razão da função. Já os adicionais de caráter remuneratório são acréscimos ao vencimento do servidor, concedidos a título definitivo ou transitório, pela decorrência do tempo de serviço (ex facto temporis), ou pelo desempenho de funções especiais (ex facto officii), ou em razão das 
condições anormais em que se realiza o serviço (propter laborem), ou, finalmente, em razão de condições pessoais do servidor (propter personam) (MEIRELLES apud MARTINs, 2004).

Segundo esse autor, o Abono foi criado como forma de incentivo à permanência do servidor em atividade, visando neutralizar a contribuição previdenciária da remuneração do servidor. Sua concessão decorre, então, de condições pessoais do servidor (propter personam) a serem aferidas individualmente. Dessa forma, ele afirma:

Impossível seria, então, reconhecer ser este possuidor de natureza indenizatória, já que não se destina a ressarcir o servidor por gastos realizados em razão de sua função, funcionando sim como um adicional incentivador à permanência em atividade do funcionário em razão de suas condições pessoais (MEIRELLES apud MARTINS, 2004).

Todos os conceitos tratados até aqui foram de fundamental importância para o entendimento e análise posterior dos dados, a fim de alcançar o objetivo pretendido.

\section{Procedimentos metodológicos}

O estudo em questão consiste em uma pesquisa qualitativa, uma vez que procura entender a realidade constituída de fenômenos socialmente construídos, cujas transformações sócio-históricas assumem aspectos que não podem ser apenas capturados pelos números da estratégia quantitativa. “[...] A mudança das coisas não pode ser indefinidamente quantitativa: transformando-se, em determinado momento, sofrem mudança qualitativa. A quantidade transforma-se em qualitativa" (LAKATOS,
1992, p. 99). Trata-se de um estudo de caso (YIN, 2001) de uma instituição federal de ensino superior (Ifes).

Essa pesquisa é, quanto aos fins, descritiva, a qual consiste em conhecer situações, costumes e atitudes, por meio da descrição detalhada da atividade, objetos, processos e pessoas. "A pesquisa descritiva expõe características de determinada população ou de determinado fenômeno. Pode também estabelecer correlações entre variáveis e definir sua natureza" (VERGARA, 2005, p. 47). Assim, o fenômeno a ser pesquisado e discutido será o "Abono Permanência como um benefício social em uma Ifes."

Como fonte de coleta de dados primários, foram realizadas entrevistas semiestruturadas de modo individual, ou seja, existia um roteiro de tópicos relativos ao problema, mas o entrevistador tinha a liberdade de fazer as perguntas necessárias, não obedecendo a rigor nenhuma estrutura formal estabelecida. Dessa forma, foi possível extrair um maior número de informações importantes para a análise. A entrevista contou com nove perguntas estruturadas, as quais tiveram como assuntos principais: 1) como e quando o Abono foi implementado na instituição; 2) como os servidores tomaram conhecimento do benefício; 3) e qual a visão dos gestores de Recursos Humanos da instituição a respeito das contribuições, limitações e motivos que levam os servidores a solicitarem o Abono em vez da aposentadoria.

A coleta de dados secundários foi realizada por meio da análise de documentos e registros, entre os quais estão os processos administrativos de Abono Permanência dos servidores da Ifes em estudos e também da observação direta dos sistemas gerenciais de processos da instituição: o Sisprocesso. 
As entrevistas e a análise dos documentos foram realizadas no quarto trimestre de 2007, com dez pessoas que trabalham diretamente com os processos de Abono Permanência na instituição. Essa escolha deve-se ao fato de que tais funcionários trabalham ou trabalhavam na Seção de Aposentadoria quando tal benefício foi implementado e também porque são eles que realizam os cálculos, formalizam e dão prosseguimento aos processos de Abono Permanência.

A finalidade principal deste estudo é responder à pergunta de pesquisa, que procurou descrever a implementação e apresentar as implicações do Abono Permanência em uma instituição federal de ensino superior e para seus servidores. As técnicas utilizadas para analisar os tipos de dados, tanto textuais quanto verbais, foram de análise de conteúdo (BARDIN, 2004). A análise de conteúdo "consiste em um instrumental metodológico que se pode aplicar a discursos diversos e a todas as formas de comunicação, seja qual for a natureza do seu suporte" (Godoy, 1995, p. 23). Entende-se que a análise de conteúdo é usada quando se quer ir além dos significados, da leitura simples do real, o que permitiu discutir os resultados advindos da análise dos assuntos 1, 2 e 3, expostos no decorrer desse procedimento metodológico.

Sendo assim, a análise das entrevistas deu-se de forma sistêmica, agregando os pontos convergentes a fim de se atingir o objetivo principal deste artigo.

\section{Resultados e discussões}

\section{Contexto organizacional}

O estudo foi realizado em uma instituição federal de ensino superior (Ifes) e contou com informações fundamentais de sua Diretoria de Recursos Humanos. Esta é responsável pelo atendimento ao servidor técnico e docente, controle de pessoal, aposentadorias e pensões, cadastros e movimentação, documentação e arquivo pessoal, desenvolvimento de pessoal, capacitação e treinamento, registros financeiros e segurança, e higiene do trabalho.

A Diretoria de Recursos Humanos funciona de segunda a sexta-feira, em

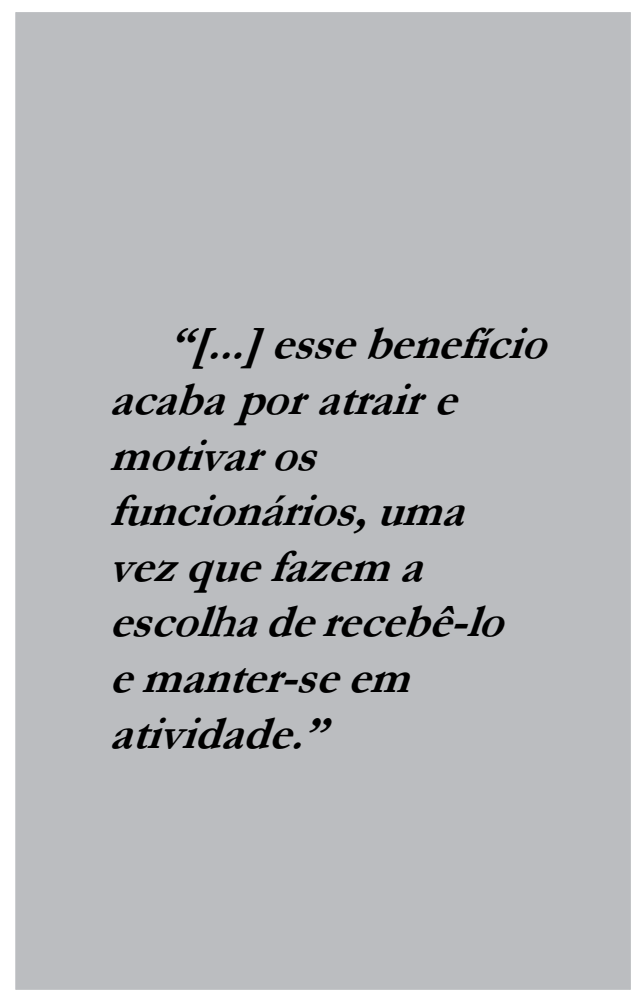

horário integral, com pausa para almoço e conta com 35 funcionários e nove estagiários.

Vinculada e subordinada à Pró-reitoria de Administração da instituição, tal diretoria está dividida em oito setores: Diretoria, Diretoria Assistente, Seção de Expediente, Seção de Atendimento ao Servidor, Serviço de Desenvolvimento de Pessoal, Serviço de Segurança e Higiene 
no Trabalho, Serviço de Registros Financeiros e Serviço de Controle de Pessoal.

Com o surgimento do Regime Jurídico Único, no final de 1990, houve a necessidade de criar uma seção que resolvesse as questões de aposentadoria, que até então eram solucionadas pelo INSS. Tais questões passaram a ser resolvidas pelo Serviço de Controle de Pessoal, até que em 1995 e 1996, devido à grande demanda, foi criada a Seção de Aposentadorias e Pensões.

Atualmente, a Seção de Aposentadorias e Pensões encontra-se vinculada ao Serviço de Controle de Pessoal e é responsável pela parte de aposentadoria, pensões, benefícios e cadastro de servidores aposentados, pensionistas e seus dependentes. A seção conta com três funcionários e atende solicitações de 3.251 servidores ativos, 1.614 aposentados e 518 pensionistas.

\section{Implementação e funcionamento}

\section{do Abono Permanência na Ifes em estudo}

O Abono Permanência é resultado da transformação de uma isenção previdenciária que existia na Emenda Constitucional no 20 de 1998. Em 2003, com a Emenda Constitucional $\mathrm{n}^{\circ}$ 41, deixou de existir tal isenção e passou a vigorar o Abono Permanência. De acordo com um entrevistado, o governo só mudou o nome. As condições para se aposentar, seja aposentadoria integral ou proporcional, são as mesmas. "A diferença entre ambos é que, na isenção, o servidor não contribuía com a previdência, já no Abono Permanência, ele contribui e recebe esse abono como rendimento", explicou.

Após a Emenda no 41, a Ifes aguardou uma orientação normativa para instruir como seria o procedimento com o Abono. "Normalmente, quando é editada uma lei, espera-se a orientação normativa que vem disciplinar e orientar a concessão do que vai ser operacionalizado", explicou outro entrevistado. No início havia dúvidas de quando realmente seria concedido, pois a Emenda no 41 é muito confusa. Então, houve dificuldade de operacionalização e a cobrança foi muito grande. A Secretaria de Recursos Humanos foi consultada e após normatizar e definir que a concessão seria a partir da implementação das condições da Emenda, muitos servidores receberam o pagamento retroativo. $\mathrm{Ou}$ seja, o Abono foi pago a partir da data em que o servidor passou a ter direito ao benefício - e não na data do requerimento para obtê-lo.

Logo após essa orientação, no início de 2004, foram concedidos os primeiros benefícios. Os servidores, tanto docentes quanto técnicos, tomaram conhecimento do benefício por meio de boletim, jornal com publicações da instituição, internet, sindicatos, associações, assembleias e, principalmente, pelos próprios servidores. Acredita-se que muitos ainda desconhecem o Abono pelo fato de que afeta a aposentadoria e não é todo mundo que está interessado no assunto; além disso, muitos servidores não frequentam os sindicatos e assembleias.

A maioria dos servidores que conhecem o Abono Permanência o chamam de "Pé-na-cova". De acordo com um entrevistado, "Pé-na-cova" é um nome pejorativo, pois as pessoas acham que só quem está próximo de morrer tem direito ao benefício, mas não é bem assim. "Há pessoas relativamente jovens, em torno dos 50 anos, que ainda vão trabalhar por mais alguns anos e já estão recebendo o Abono", salientou. É um incentivo ao servidor para permanecer na ativa (SERTÃO, 2005); não significa que o governo federal ou o serviço público esteja encarando o servidor como próximo da morte. 
No ano de 2004, foram concedidos 255 benefícios, sendo que, desse total, 46 eram de docentes e 209 de técnicos administrativos. Em 2005, o total não passou de 20 benefícios, sendo 14 de docentes e seis de técnicos. Já em 2006, foram 44 concessões, das quais 28 de docentes e 16 de técnicos. Em 2007, foram concedidos 46 benefícios, sendo 19 de docentes e 27 de técnicos. Portanto, desde a sua implementação na instituição, já foram concedidos 365 benefícios de Abono Permanência.

Normalmente, o tempo que se leva desde o pedido do Abono até sua concessão gira em torno de sete a 15 dias. Isso porque, antes de o processo ser aberto, o servidor já compareceu à Seção de Aposentadoria e Pensões da Diretoria de Recursos Humanos da instituição e já foram feitos os cálculos. Com a abertura do processo de solicitação do Abono Permanência, caso a pasta do servidor esteja com toda a documentação, só é necessário anexar a cópia dos documentos de averbação e os outros dados. O sistema, que é todo informatizado, possui o tempo de trabalho do servidor, a data de ingresso no serviço público e o cargo que ocupa. Basta formalizar tudo, passar pelo diretor e lançar o Abono no sistema de pagamento (Siape). Outro ponto a se observar é a data em que a folha de pagamento é fechada. Normalmente, a do mês seguinte fica aberta até a segunda semana do mês em curso. Supondo que o processo é concluído no dia 5 de novembro e a folha de pagamento fecha por volta do dia 13, é possível ser lançado o Abono para pagamento no mês seguinte. Agora, se o processo for concluído no dia 15 de novembro, por exemplo, a folha de novembro já estará fechada. Nesse caso, só será possível lançar o Abono na folha de pagamento de dezembro.
Atualmente, todos os cálculos são realizados manualmente e com o auxílio de um sistema on line desenvolvido pela Central de Processamento de Dados (CPD) da instituição, juntamente com a Seção de Aposentadoria e Pensões. Tal sistema, que está em fase de testes, permitirá aos servidores saber quando pleitear aposentadoria ou o Abono Permanência.

Verificou-se, mediante a realização de entrevistas, que os servidores solicitam o benefício, na maior parte das vezes, por questões financeiras. Primeiramente porque, estando em atividade, o trabalhador não perde outros benefícios que perderia caso se aposentasse, como o vale-alimentação, o adicional de insalubridade e a função que ocupa. Segundo, porque as regras de aposentadoria exigem a idade de 60 anos para aposentadoria integral e, a partir de 53 anos, para a aposentadoria proporcional, em alguns casos, o servidor já tem direito ao Abono. De acordo com as entrevistas, a aposentadoria proporcional não é uma aposentadoria boa, pois "o servidor acaba perdendo muito do que vai receber". Por esse motivo, prefere aguardar a aposentadoria integral e, enquanto espera, recebe o Abono.

Em outros casos, os servidores fazem a opção pelo Abono porque querem continuar a trabalhar e não possuem outra atividade. Acredita-se que no serviço público falte motivação e incentivo para as pessoas trabalharem. Essa foi uma forma de o governo manter por mais tempo o pessoal, já que há menos contratações. Além do mais, com isso a folha de pessoal tornase menos onerosa. "O Abono Permanência tem o objetivo [...] de promover maior economia ao Estado que, com a permanência do servidor na ativa, consegue postergar a dupla despesa de pagar proventos a este e remuneração ao que o substituirá" (SERTÃo, 2005, p. 2). 
Pode-se perceber que os entrevistados acreditam que a contribuição do Abono Permanência acaba mantendo o servidor mais tempo em atividade. Com isso, prende o bom e experiente profissional por mais tempo, postergando sua aposentadoria. A grande importância está em poder contar com a experiência dessas pessoas, principalmente para quem está começando.

A despeito dos resultados gerais, o Quadro 1 apresenta as principais implicações da implementação do Abono Permanência no caso da Ifes analisada. Pode-se observar que as contribuições e limitações sintetizadas sobre a aplicação do Abono Permanência, no caso em estudo, são de fundamental importância. Além de reafirmarem o ponto de vista de alguns autores, de que os trabalhadores selecionam os benefícios de acordo com suas necessidades individuais - no caso do Abono, por motivação pessoal ou para não perder outros benefícios caso se aposentasse -, demonstram que nem sempre os benefícios oferecidos atendem a todos os funcionários de maneira satisfatória, como ressaltou um gestor entrevistado a respeito do Abono para determinados tetos salariais.

\section{Considerações finais}

Este trabalho, em consonância com o objetivo proposto, apresentou a implementação do Abono Permanência em uma instituição federal de ensino superior e procurou descrever o funcionamento, a operacionalização e as implicações do benefício para seus servidores e para a própria instituição.

Nesse sentido buscou-se, a partir das entrevistas, ampliar e enriquecer a discussão sobre os benefícios sociais na administração pública e quais as contribuições e limitações dos benefícios na vida dessas pessoas.

Pode-se perceber que, em conformidade ao objetivo que foi criado, os servidores acreditam que a contribuição do Abono Permanência é mantê-los por mais tempo em atividade, adiando assim a aposentadoria, e também promover maior economia aos cofres públicos.

\section{Quadro 1: Contribuições e Limitações do Abono Permanência no caso da Ifes em estudo}

\begin{tabular}{|c|c|}
\hline Contribuições & Limitações \\
\hline Incentiva o servidor a permanecer em atividade. & \multirow{2}{*}{$\begin{array}{l}\text { O servidor continua pagando imposto } \\
\text { de renda, em vez da antiga isenção de } \\
\text { contribuição previdenciária. }\end{array}$} \\
\hline $\begin{array}{l}\text { Promove maior economia ao Estado, postergando a } \\
\text { dupla despesa de pagar proventos a este e remuneração } \\
\text { ao que o substituirá. }\end{array}$ & \\
\hline Mantém a arrecadação dos fundos de previdência. & \multirow{3}{*}{$\begin{array}{l}\text { Para determinados tetos salariais, não } \\
\text { vale a pena requerer o benefício, pois esse } \\
\text { fará pouca ou nenhuma diferença salarial. }\end{array}$} \\
\hline $\begin{array}{l}\text { O servidor continua recebendo outros benefícios } \\
\text { que perderia caso se aposentasse. }\end{array}$ & \\
\hline $\begin{array}{l}\text { Motivação pessoal do servidor em continuar } \\
\text { trabalhando. }\end{array}$ & \\
\hline
\end{tabular}

Fonte: Elaboração própria 
De acordo com a literatura de gestão de pessoas, vimos ainda que esse benefício acaba por atrair e motivar os funcionários, uma vez que fazem a escolha de recebê-lo e manter-se em atividade. Entretanto, surgiram algumas limitações que precisam ser consideradas. A partir do estudo realizado na Ifes neste artigo, em alguns casos, se o servidor tiver o tempo integral não vale a pena fazer o pedido desse Abono. Pois, com a aposentadoria integral, até determinado teto salarial, o servidor fica isento da contribuição; recebendo o Abono, ele contribui. Ou seja, recebe o Abono e tem descontada a contribuição previdenciária. Nesses casos, só é vantajoso permanecer em atividade se o servidor realmente quiser ou por motivos pessoais, pois no final das contas não vai fazer muita diferença.

Conclui-se, portanto, que o Abono Permanência é um benefício importante na gestão pública, pois mantém as pessoas mais experientes por mais tempo em atividade e promove um menor custeio do Estado. Além disso, é requerido não só por questões financeiras, como também pessoais e motivacionais.
Vale ressaltar que esses são os primeiros passos deste estudo na área de gestão de pessoas no contexto da Ifes e a visão de seus gestores a respeito do assunto. Pode-se reforçar que a pesquisa se concentrou somente nas pessoas que trabalham com tal benefício, o que é um limitador. No entanto, os resultados alcançados são capazes de propiciar bases para estudos futuros, uma vez que podem ser feitos estudos similares e comparativos com as pessoas que também recebem o benefício.

Por último, é importante destacar que este estudo contribui nas discussões sobre benefícios na gestão de pessoas, em especial na instituição federal de ensino superior em questão, apresentando as vantagens de se requerer o benefício e as desvantagens ou limitações que merecem ser mais discutidas dentro da Ifes e por seus profissionais. Além disso, é um benefício a ser estudado com mais profundidade e tomado como potencial para instituições privadas, visto que só é oferecido na esfera pública e pode gerar contribuições e desdobramentos semelhantes na esfera privada e no terceiro setor.

(Artigo recebido em outubro de 2008. Versão final em fevereiro de 2009). 


\section{Referências}

Araújo, Luis César G. de. Gestão de Pessoas. São Paulo: Atlas, 2006.

Bardin, L. Análise de conteúdo. 3. ed. Lisboa: Edições 70, 2004.

Bohlander, George W.; Sneld, Scott; Sherman, Arthur. Administração de Recursos Humanos. São Paulo: Pioneira Thomson Learning, 2005.

Brasil. Emenda Constitucional n 41, de 31 de Dezembro de 2003. Diário Oficial, fev. 2004.

Bratton, John; Gold, Jeffrey. Human Resource Management. Theory and Practice. 2 ed. Macmillan Business, 1999.

FrançA, Ana Cristina Limongi. Práticas de Recursos Humanos: PRH: conceitos, ferramentas e procedimentos. São Paulo: Atlas, 2007.

Fundação Universidade Federal do Rio Grande - FURG. Abono Permanência. Disponível em: <http://www4.furg.br/sarh/arquivos/procedimentos/000037.pdf >. Acesso em: 20 set. 2007.

Governo do Estado de São Paulo - GESP. Instrução da Unidade Central de Recursos Humanos. 29 out. 2004. Disponível em: <http://www.e-folha.sp.gov.br/contr-prev/ instrucao/Inst_UCRH_02_2004.doc >. Acesso em: 20 set. 2007.

Godoy, Arilda Schmidt. Pesquisa Qualitativa: Tipos Fundamentais. Revista de Administração de Empresas - RAE. São Paulo, USP, v. 35, n.3, p. 20-29, mai./jun. 1995.

Lacombe, F. J. M. Recursos Humanos: princípios e tendências. São Paulo: Saraiva, 2005.

Lakatos, E. M.; Marconi, M. Metodologia do Trabalho Científico. 4. ed. São Paulo: Atlas, 1992.

Martins, Bruno Sá Freire. A natureza jurídica do abono de permanência. Jus Navigandi. Teresina, ano 9, n. 538, 27 dez. 2004. Disponível em: < http://jus2.uol.com.br/doutrina/ texto.asp?id=6107>. Acesso em: 04 set. 2007.

Sertão, Alex Sandro Lial. Abono de Permanência. 25 mai. 2005. Artigo. Disponível em: $<$ http://www.tce.pi.gov.br/documentos/artigos/abono_permanencia.pdf $>$. Acesso em: 04 set. 2007.

Universidade Federal de São Carlos - UFSCAR. Implicações da Reforma da Previdência para o Servidor Público. Mai. 2004. Disponível em: <http://www.srh.ufscar.br/ Duvidas\%20aposentadoria.doc >. Acesso em: 04 set. 2007.

Vergara, Sylvia Constant. Métodos de Pesquisa em Administração. São Paulo: Atlas, 2005. . Projetos e Relatórios de Pesquisa em Administração. 6. ed. São Paulo: Atlas, 2005. YIN, R. K. Estudo de Caso: planejamento e método. 2.ed. Porto Alegre: Bookman, 2001. 


\section{Resumo - Resumen - Abstract}

\section{Abono Permanência em uma instituição federal de ensino superior: aplicação e desdobramentos \\ Roberta Martins Xavier e Magnus Luiz Emmendoerfer}

A preocupação principal deste artigo é descrever a implementação do Abono Permanência em uma Instituição Federal de Ensino Superior e as implicações que o mesmo acarretou a seus servidores e à própria instituição. O objetivo pretendido aqui não está em exaurir o assunto então tratado, mas mostrar o quanto este pode ser importante, partindo do pressuposto de seu significado intrínseco na motivação para o trabalho. O principal interessado no assunto é o servidor público e esse pode usufruir do benefício dado sua idade para aposentar. Trata-se de uma pesquisa descritiva, cuja coleta se deu por entrevistas semiestruturadas e individuais com funcionários que trabalham diretamente com os processos de Abono Permanência, e também pela análise de documentos e observação direta dos sistemas gerenciais de processos administrativos da instituição. Este estudo contribui nas discussões sobre benefícios sociais na Gestão de Pessoas e a utilização desses recursos na administração pública. Pode-se concluir que o Abono Permanência traz diversas contribuições como, por exemplo, a motivação pessoal em continuar trabalhando, porém, apresenta algumas limitações no próprio incentivo ao benefício, que pode não ser interessante em determinados tetos salariais.

Palavras-chave: gestão de pessoas, benefícios sociais, servidor público.

\section{Abono Permanencia en una institución federal de enseñanza superior: aplicación y desdoblamientos \\ Roberta Martins Xavier y Magnus Luiz Emmendoerfer}

La principal preocupación de este artículo es describir la implementación del Abono Permanencia en una Universidad y las implicaciones que el mismo acarreó a sus funcionarios y a la propia Institución. El objetivo del artículo es descoyuntar el tema tratado, pero mostrar el cuanto éste puede ser importante, partindo de la hipótesis de su significado intrínseco en la motivación para el trabajo. El principal interesado en el tema es el funcionario, que puede disfrutar de este beneficio de acuerdo con su edad para jubilarse. Se trata de una investigación descriptiva, cuya recolección de datos fue a través de entrevistas semiestructuradas e individuales con funcionarios que trabajan directamente con los procesos del Abono Permanencia, y también a través del análisis de documentos y observación directa de los sistemas gerenciales de procesos administrativos de la Universidad. Este estudio contribuye a las discusiones sobre beneficios sociales en la Gestión de Personas y la utilización de estos recursos en la administración pública. Se puede concluir que el Abono Permanencia trae diversas contribuciones como, por ejemplo, la motivación personal para continuar trabajando, pero, presenta algunas limitaciones en el propio incentivo al beneficio, que puede no ser interesante para determinados sueldos.

Palabras clave: gestión de personas, beneficios sociales, funcionario público.

\section{Bonus Permanence in a federal university: application and developments Roberta Martins Xavier and Magnus Luiz Emmendoerfer}

The main concern of this paper is to describe the implementation of "Bonus Permanence" in a Federal University and the contributions it brings to the institution itself. We do not intend to exhaust the subject, but to show its importance based on the assumption of its intrinsic motivational meaning at work. The most interested readers in the subject are public employees, mainly the ones 
who can enjoy that benefit at retiring age. It is a descriptive research, the data was collected through semi-structured interviews and through individual interviews with employees that work directly with "Bonus Permanence" processes, and also through analysis of documents and direct observation of the management systems of administrative processes at this university. This study contributes to discussions on social benefits in People Management and on the use of those resources in the public administration. It was possible to conclude that the "Bonus Permanence" brings several contributions as, for example, personal motivation to continue working. However, it presents some limitations also, as the "Bonnus Permanence" becomes uninteresting at certain salary levels.

Keywords: people management, social benefits, public employee

Roberta Martins Xavier

Estudante de Administração da Universidade Federal de Viçosa. Contato: roberta.mx@hotmail.com

Magnus Luiz Emmendoerfer

Professor de Administração da Universidade Federal de Viçosa; doutorando em Ciências Humanas - Sociologia e Política - pela Universidade Federal de Minas Gerais e mestre em Administração pela Universidade Federal de Santa Catarina. Contato: magnus@ufv.br 